\title{
New methods of spatial analysis in urban gardens inform future vegetation surveying
}

\author{
Monika H. Egerer (D) B Benjamin Wagner • Brenda B. Lin • Dave Kendal • \\ Kai Zhu
}

Received: 14 August 2019/Accepted: 18 January 2020/Published online: 10 February 2020

(C) The Author(s) 2020

\begin{abstract}
Context Land use change requires measuring shifting patterns in biodiversity at various spatial scales to inform landscape management. Assessing vegetation change at different scales is challenging in urban ecosystems managed by many individuals. Thus, we do not know much about the structure and function of green spaces that support biodiversity.

Objective We aim to understand how vegetation structure and function indicators in urban community gardens vary with spatial scale, applying new and traditional methods in landscape ecology to inform future research and application.
\end{abstract}

Electronic supplementary material The online version of this article (https://doi.org/10.1007/s10980-020-00974-1) contains supplementary material, which is available to authorized users.

M. H. Egerer $(\bowtie) \cdot$ K. Zhu

Environmental Studies Department, University of California - Santa Cruz, 1156 High St., Santa Cruz, CA 95064, USA

e-mail: monika.egerer@tu-berlin.de

\section{H. Egerer}

Department of Ecology, Chair of Ecosystem Sciences/

Plant Ecology, Technische Universität Berlin,

Rothenburgstrasse 12, 12165 Berlin, Germany

B. Wagner · D. Kendal

School of Ecosystem and Forest Sciences, The University of Melbourne, 500 Yarra Boulevard, Richmond,

VIC 3121, Australia
Methods We performed two methods to assess garden vegetation structure (height) and function (species diversity, cover) at the garden- and garden plot scale. First, we used traditional field sampling to estimate garden vegetation at the garden scale $\left(1 \mathrm{~m}^{2}\right.$ quadrats along transects) and at the plot scale (estimated within entire plot) to measure height, diversity and cover. Second, we used UAV aerial imagery to derive measures of garden and plot vegetation using canopy height models (CHMs). We evaluated differences in CHMs at each scale across the gardens, and compared field and UAV-derived measures.

Results Garden vegetation characteristics vary with spatial scale. Plant species richness and vegetation cover, but not height, related to UAV-derived imagery.

\section{B. B. Lin}

CSIRO Land and Water Flagship, 107-121 Station St., Aspendale, VIC 3195, Australia

D. Kendal

School of Technology, Environments and Design,

University of Tasmania, Hobart, TAS 7001, Australia 
Conclusions New technologies paired with traditional field methods can together inform how vegetation structure and function vary with spatial scale in urban landscapes. Spatial scale is key to accurate and meaningful urban vegetation analyses. New and traditional methods in urban ecology research should develop together to improve and streamline their future application.

Keywords Urban agriculture · Plant diversity · Garden · Unmanned aerial vehicle · Remote sensing

\section{Introduction}

Rapid land use conversion has changed the distribution, composition and function of biodiversity within ecosystems across landscapes (Foley et al. 2005). Habitat fragmentation, urbanization, and biotic homogenization are particularly responsible for biodiversity change and decline (Fahrig 2003; GámezVirués et al. 2015; Knop 2016). One of the greatest challenges is to measure shifting patterns in biodiversity in the context of landscape change (Anderson 2018). Understanding how biodiversity responds to land use heterogeneity versus homogeneity informs landscape management (Lindenmayer et al. 2008), but it is necessary to evaluate heterogeneity at different spatial scales because ecological processes underlying ecosystem functions may vary with spatial scale $(\mathrm{Wu}$ 2004). Heterogeneity is especially important to measure in urban ecosystems managed by many individuals that contribute great amounts to the vegetation diversity, structure and biodiversity conservation in cities ( $>50 \%$ of urban green space in many cities; (Goddard et al. 2010)). Yet we know little about their ecological functions such as nutrient cycling or carbon sequestration (Cook et al. 2012) that provide ecosystem services due to site access. In this study, we investigate how vegetation species diversity, cover and height as indicators of ecosystem structure and function in an urban green space type (urban community gardens) vary at different spatial resolutions across an urban landscape by applying new technologies in ecology in combination with field assessments that are frequently used in urban ecology. We explore some of the ecological implications of changes in vegetation across different spatial scales, and look forward to how to bridge and improve traditional field methods with new technologies in urban landscape ecology research.

Urban and agricultural land use transformation are two dominant drivers of ecological change within habitat patches. In particular, urban landscapes differ greatly in the amount of impervious cover, building density and urban habitat types, composition and function (Lin and Fuller 2013). Cities can act as reservoirs for biodiversity by hosting many native and endangered species in addition to exotic and ornamental species often associated with urbanization (Alvey 2006). This biodiversity within urban habitats generally varies within (Hostetler and Holling 2000; Penone et al. 2013) and across spatial scales (McDonnell and Hahs 2008). Some small habitat patches within urban areas can harbor surprisingly high species richness of plants and animals (Alvey 2006; Egerer et al. 2016). Furthermore, a positive association between biodiversity and human population density is dependent on spatial grain and extent (Pautasso 2007). Ecological community composition, structure and function is related to biodiversity within a habitat and the scale at which biodiversity is measured (Andersson et al. 2015). Thus it is critical to measure patterns of urban biodiversity within different habitats at different spatial scales given contemporary urban biodiversity loss (Ricketts and Imhoff 2003; McKinney 2006; Flynn et al. 2009) and the role of urban habitats for biodiversity conservation and ecosystem service provision (Alvey 2006), including temperature regulation and recreation.

Urban agroecosystems provide an interesting system to investigate biodiversity patterns at various spatial scales with implications for ecosystem service management. Urban agroecosystems, including home gardens, community gardens and farms, are habitats within cities, designed for agricultural production, often harboring hundreds of native and non-native plant species of crops, ornamentals, herbs, fruit and non-fruiting trees, "weeds" and grasses (Loram et al. 2008; Guitart et al. 2012). Vegetation within urban agroecosystems including annual vegetable crops and perennial trees and shrubs provide important ecosystem services including food provision, carbon sequestration, storm water runoff control, and temperature regulation (Lovell 2010; Lovell and Taylor 2013; Lin et al. 2015). In addition, garden vegetation affects animal pollinators and natureal enemies that support 
pollination and pest control linked to sustainable food production (Lin et al. 2015). Community allotment gardens (agroecosystems divided into plots managed by individual or multiple households) are common green spaces across urban regions globally that range in size (from $<1$ ha to $>10$ ha), habitat structure, and number of participants $(<10$ to $>1000)$ (Drescher et al. 2006; Speak et al. 2015; Bell et al. 2016; Lin and Egerer 2017). Community allotment gardens are of special ecological interest, because up to hundreds of people with different preferences, values, and management practices may participate to elevate the number and diversity of plant populations. Ecosystem service degradation in urban landscapes also make these designed habitats important for conserving ecosystem service providers including pollinators and natural enemies (Andersson et al. 2007) that rely on diverse planned and ambient plant species for nectar, pollen or prey (Lin et al. 2015). Because high plant species diversity is associated with greater ecosystem function (Hooper and Vitousek 1997; Hooper et al. 2005), measuring garden vegetation is relevant to urban conservationists and planners because these systems are a common green space that can benefit thousands of urban residents across various geographic contexts (Drescher et al. 2006; Guitart et al. 2012; Bell et al. 2016; Spilková and Vágner 2017). In addition, measuring vegetation is interesting both at the scale of an individual's management (within a garden plot) and at the scale of the habitat (the whole garden) because individual vegetation management practices and preferences largely differ (Egerer et al. 2019) and ecosystem service providers may respond differently to changes in species diversity or composition at these different scales (e.g., bee communities respond to both floral clustering within plots and floral density across the garden; (Plascencia and Philpott 2017)). Furthermore, long standing vegetation such as trees and shrubs that are important for carbon sequestration and temperature regulation services may be managed at the garden scale (e.g., in a community-managed orchard), and less within individual plots that are more dynamic in management due to membership turnover. Thus, it is important to understand vegetation management at different scales, specifically how patterns and relationships differ, because of the ecological applications regarding ecosystem service management (Speak et al. 2015).
New technological advancements in remote sensing have heightened researchers' capacity to collect fine-scale data on ecosystem features within various landscape types at various scales to answer questions around how, for example, vegetation varies with spatial scale (Cunliffe et al. 2016; Duffy et al. 2018). Unmanned aerial vehicles (UAVs), or "drones", can collect high resolution vegetation data at low cost and are increasingly employed in agroecosystems to pinpoint pest outbreaks (Yue et al. 2012) (i.e., "precision agriculture"); grasslands to measure plant chlorophyll content ( $\mathrm{Lu}$ et al. 2017); and forests to detect insect infestations (Näsi et al. 2015; Murfitt et al. 2016). UAVs also have potential to assess fine scale land use heterogeneity and patterns of biodiversity or vegetation in urban environments (Feng et al. 2015; Gaitani et al. 2017), though they may be difficult to utilize because of city laws regarding flight height or airport regulations (e.g., CASA Regulations in Australia; (Civil Aviation Safety Authority 2019)). UAVs may be able to access otherwise difficult to survey city spaces such as private green spaces (e.g. home gardens), and may be a useful tool in documenting vegetation characteristics in these otherwise poorly documented urban habitats. Satellite imagery, LiDAR, and hyperspectral imagery have relatively recently been applied in urban areas by researchers to measure vegetation across various spatial scales for the urban forest (e.g., measuring tree species identity; (Zhang and Qiu 2012)), front and backyards (e.g. measuring vegetation structure; (Ossola et al. 2019)), and community gardens (e.g. measuring tree canopy versus grass cover; (Anderson et al. 2019)). This technology has certainly improved researchers' ability to assess changes in vegetation structure with implications for urban ecosystem management and service provision. Yet the application of drone technology in urban environments could significantly heighten the capacity to collect even more detailed information about biodiversity and ecosystem function at multiple, especially fine spatial scales and at a fraction of the cost of other remote sensing in similar resolution (Koh and Wich 2012; Marvin et al. 2016). This could provide relevant information to habitat managers interested in better managing urban environments including urban agroecosystems for provisioning (e.g. food production) and regulating (e.g. temperature regulation, pest control) ecosystem services correlated with characteristics of vegetation management 
(Elmqvist et al. 2016; Langemeyer et al. 2018). However, the precision and accuracy of UAVs to assess vegetation management related to ecosystem function and services is still less understood in diverse urban ecosystems with high plant species richness in small areas such as garden plots, and needs to be adjusted and parametrized (e.g., relating data collected using UAVs to common vegetation measurements taken by researchers) (Erena et al. 2016; Goodbody et al. 2018). More studies are needed to better relate environmental data on vegetation collected in the field using common methods in urban ecology with data collected using UAVs in urban environments. Studies that bridge traditionally employed field methods in urban ecology with new evolving methods that harness new technologies may best be able to assess and describe the ecological reality in complex urban systems. At the onset of the use of new technologies such as UAVs in urban landscape ecology, case studies are needed to assess what data needs to be collected by which platform (aerial or ground/field based) to derive meaningful and reproducible answers to today's research questions and to make best use of both approaches.

In this study, we use urban community gardens as a system to ask questions about ecosystem vegetation structure and function in relation to spatial scale. We use a new landscape ecology technology, low cost remote sensing UAVs, in parallel with traditional field measurements common in urban ecology to ask how this new technology assesses indicators of garden vegetation structure and function at two different scales-the entire garden and individual gardener's plots. In addition, we consider how new technologies and traditional field methods could be better codeveloped and employed in urban landscape ecology research to further ecological understanding of urban ecosystem structure and functions. Specifically, we asked three questions: (1) How do urban garden vegetation structure (plant height) and function (plant species diversity/cover) measured at two different spatial scales using UAVs and field methods vary with scale? (2) How does land cover data derived from UAV imagery relate to common basic field measurements of urban garden vegetation structure and function at two spatial scales? And (3) what are ways forward to best bridge new technology methods with traditional field methods in urban landscape ecology and improve their application in future studies? Here, we used plant species richness and amount of vegetation cover as indicators of ecosystem function (Hooper and Vitousek 1997; Hooper et al. 2005), and plant height as an indicator of ecosystem structure (Parker 1995). We hypothesized that values commonly derived from UAV imagery (canopy height models) are good indicators of both vegetation structure and function, and have implication for ecosystem service provisioning of these systems. Collectively, our aims were to: determine how garden vegetation varies at different scales in and across urban gardens in the context of service provision and management implications; relate traditional field methods in urban ecology with new technology-based methods in landscape ecology; assess the ability of a new technology to collect the relevant data to answer these research questions; and guide future application of UAV technologies and combined field assessments in urban landscapes by ecologists.

\section{Methods}

\section{Study system}

The study area was ten community allotment gardens in the Greater Metropolitan Area of Melbourne, Victoria, Australia (population 4.7 million, study area center point: $37^{\circ} 50^{\prime} 8.60^{\prime \prime} \mathrm{S} 145^{\circ} 2^{\prime} 15.31^{\prime \prime} \mathrm{E}$ ) (Fig. 1). The gardens are overseen by the city government but are managed by individual gardeners who lease single allotment plots to cultivate plants as they choose, under rules of the garden management. Some gardens also have common areas including orchards and herb gardens that all gardeners collectively manage. The gardens were established between 6 to 38 years ago, are from 584 to $6801 \mathrm{~m}^{2}$ in size, and have between 25 and 124 allotment plots. We studied the system at two spatial scales: (1) the garden (henceforth 'garden scale'), and (2) the individual gardener allotment plot ('plot scale'). We worked with each of the nine community garden managers to randomly select four garden plots distributed throughout the garden of gardeners willing to allow us access to their plot ( $n=36$ in total). The number of plots surveyed in the field was constrained due to site and time access, and introduces a limitation to our plot to garden scale comparison. 


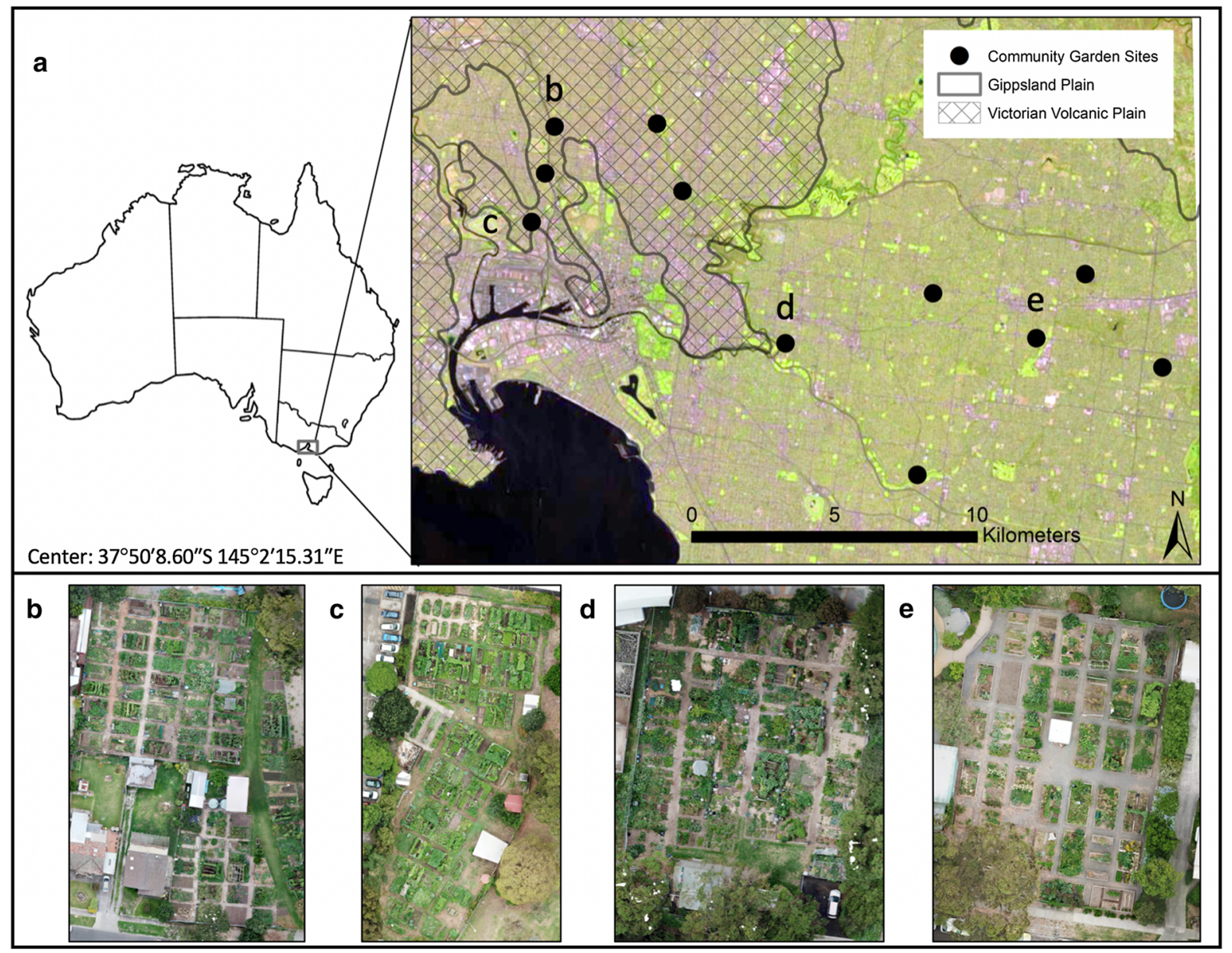

Fig. 1 Distribution of community garden study sites across the Greater Metropolitan Area of Melbourne, Victoria, Australia (a). The gardens are located across an urbanization gradient in two bioregions (Gippsland Plain and the Victorian

\section{Field assessment}

We used common field methods, traditional in urban ecology, to assess garden vegetation at the garden scale and at the within garden plot scale (Online Appendix 1). Specifically, we sampled plant species diversity, vegetation ground cover composition, and tallest vegetation height at the garden scale and at the plot scale under the assumption that these are good indicators of vegetation-related ecosystem function and structure (Hooper and Vitousek 1997; Hooper et al. 2005) with implication for ecosystem service provisioning from gardens. Here we assumed that all plant species play some functional role in gardens and included all annual and perennial plant species, both
Volcanic Plain). Locations of study sites (latitude, longitude) include: b - 37.46, 144.56; c - 37.79, 144.93; d - 37.83, 145.03; and $\mathbf{e}-37.83,145.13$. The location of the center point of the study region given in panel a

planned (vegetable, ornamental plants) and ambient (e.g. 'weeds'). At the garden scale, we placed transects every $5 \mathrm{~m}$ across the width of the garden. Along the transects, we randomly placed $1 \times 1 \mathrm{~m}$ quadrats within which we recorded the species identity of all plants present, took the height of the tallest non-woody vegetation $(\mathrm{cm})$, and estimated the percent of herbaceous vegetation ground cover including crop plants, weed plants and grass (i.e., versus bare soil, mulch, rock). Because gardens were of different sizes, they had varied numbers of transects and we proportionally increased the number of $1 \times 1 \mathrm{~m}$ quadrats relative to garden size. All gardens had a minimum of eight $1 \times 1$ m quadrats, and we added one $1 \times 1 \mathrm{~m}$ quadrat for every additional $500 \mathrm{~m}^{2}$ (resulting a minimum of 
eight quadrats, up to 19 quadrats in the largest garden). We divided the number of quadrats by the number of transects in order to determine how many quadrats to sample along each transect (minimum of two, up to five quadrats per transect). For each garden, we pooled the species richness, average vegetation height, and percent of herbaceous vegetation cover for all quadrats along the transects (i.e. garden scale measurements). At the plot scale, we similarly sampled the species identity of plants present, took the height of the tallest non-woody vegetation, and estimated the percent of herbaceous vegetation cover in the entire plot. We measured the size of each gardener's plot $\left(\mathrm{m}^{2}\right)$ because plots were of different sizes across the ten gardens. Total plant species richness and average vegetation cover was calculated for each garden plot (i.e. plot scale measurements). Collectively, these data provided us with field vegetation measurements commonly collected (e.g. species diversity) at the plot and garden scale.

UAV system and aerial imagery collection

We used a compact commercial DJI Mavic multirotor UAV (DJI Co. Shenzhen, China) to carry out autopiloted flights over the accessible urban gardens (for specifications see Online Appendix 2). UAV flight paths for each garden were planned using QGIS 2.18 (QGIS Development Team 2018) and DJI Ground Station Pro (https://www.dji.com) and were directed by the authors using the respective application on a tablet computer. The maximum vertical distance between the ground and the drone was $120 \mathrm{~m}$ and $30 \mathrm{~m}$ away from any individuals on the ground in accordance to the Australian Civil Aviation Safety Authority (CASA) and all flights were registered under an aviation reference number. All flights were carried out in overcast weather conditions within $8 \mathrm{~h}$ on the same calendar day to maintain consistent ambient light conditions. To ensure data comparability across all gardens, we chose a $70 \mathrm{~m}$ flight altitude as this was the minimum altitude possible to avoid all restrictions in one of the gardens that had tall apartment blocks in close proximity. Although higher resolution can be achieved at lower altitudes, the complexity of the urban environment including overhead power lines, tall buildings or areas of infrastructure such as highways and railways that cannot be flown over according to CASA, restricted the planning of flights. An average flight altitude of $70 \mathrm{~m}$ resulted in an image resolution of $2.5 \mathrm{~cm}$ per pixel. Further details regarding flight and imagery collection can be found in Table 1 and Online Appendix 2.

Creation of canopy height models

Acquired aerial images were processed using Agisoft Photoscan Pro 1.4.4 (https://www.agisoft.com/) based on the geometric principle of calculating the distance between two points in space to result in single georeferenced orthomosaics for each garden (Wolf and Dewitt 2000; Mikhail et al. 2001). We applied photometric calibrations to overexposed or dark images using Photoscan's 'calibrate colors' function, and we bulk processed images to achieve similar brightness, contrast and exposure levels in all images for each garden. We cross-referenced image ground accuracy with ground measurements of the garden and plot centers to confirm $<1 \mathrm{~cm}$ accuracy.

We created 3D point clouds of each garden using the UAV-acquired RGB imagery (Fig. 2). Point clouds from photogrammetry are an alternative to laser scanning approaches such airborne or UAV LiDAR and are easier to derive and create from commercial drone systems that provide similar accuracy at a fraction of the cost and processing effort. Point clouds based on RGB imagery and photogrammetry can be derived from UAV platforms that are much smaller, lighter and cheaper than those carrying expensive and sensitive LiDAR sensors. This gives the photogrammetric approach an advantage in urban landscapes as lighter and smaller drones can be used in more space-restricted areas and require fewer permits to fly (Ni et al. 2015; Herrero-Huerta et al. 2016; Stone et al. 2016). Point clouds were in photogrammetric processing to first derive a digital terrain model and orthomosaics of each garden in true color (RGB). The processing of the point clouds into rasters was carried out using the $\mathrm{R}$ statistical environment version 3.2.4 (R Development Core Team 2016) and packages lidR (Roussel and Auty 2018), raster (Hijmans 2015), rgdal (Bivand et al. 2018), and EBImage (Pau et al. 2010). The package lidR is based on LAStools (https:// rapidlasso.com/).

Using the initial point cloud, we extracted ground points to normalize and flatten the surface to set ground elevation to $0 \mathrm{~m}$. We then used the normalized point cloud to derive a canopy height model (CHM) 
Table 1 Summary statistics for the community gardens (a) and garden plots (b) studied for each method (UAV or field) used

\begin{tabular}{|c|c|c|c|c|c|c|c|}
\hline Scale & Method & Variable & Mean & SD & Median & Min & Max \\
\hline \multirow[t]{9}{*}{ (a) Garden } & \multirow[t]{6}{*}{ UAV } & Mean (CHM) & 1.04 & 0.51 & 1.11 & 0.26 & 1.69 \\
\hline & & $\mathrm{SD}(\mathrm{CHM})$ & 0.64 & 0.12 & 0.64 & 0.45 & 0.84 \\
\hline & & Minimum (CHM) & 0.00 & 0.22 & 0.04 & 0.00 & 0.63 \\
\hline & & Maximum (CHM) & 3.44 & 0.05 & 3.44 & 3.26 & 3.49 \\
\hline & & Vegetation cover (CHM) & 84.99 & 22.98 & 98.92 & 39.82 & 100 \\
\hline & & Garden size $\left(\mathrm{m}^{2}\right)$ & 2174.44 & 1990.58 & 1201.00 & 591.00 & 6801.00 \\
\hline & \multirow[t]{3}{*}{ Field } & Plant sp richness (\#) & 32.22 & 8.36 & 29.00 & 22.00 & 47.00 \\
\hline & & Vegetation cover $(\%)$ & 67.65 & 25.87 & 63.95 & 37.12 & 127.69 \\
\hline & & Tallest vegetation $(\mathrm{cm})$ & 74.63 & 19.10 & 79.70 & 48.29 & 99.86 \\
\hline \multirow[t]{9}{*}{ (b) Plot } & \multirow[t]{6}{*}{ UAV } & Mean (CHM) & 1.21 & 0.61 & 1.23 & 0.19 & 3.13 \\
\hline & & $\mathrm{SD}(\mathrm{CHM})$ & 0.45 & 0.18 & 0.46 & 0.16 & 0.87 \\
\hline & & Minimum (CHM) & 0.40 & 0.42 & 0.30 & 0.00 & 1.80 \\
\hline & & Maximum (CHM) & 2.66 & 0.79 & 2.80 & 1.01 & 3.79 \\
\hline & & Vegetation cover (CHM) & 86.15 & 26.72 & 100.00 & 11.56 & 100.00 \\
\hline & & Plot size $\left(\mathrm{m}^{2}\right)$ & 16.24 & 7.44 & 16.00 & 3.00 & 35.00 \\
\hline & \multirow[t]{3}{*}{ Field } & Plant sp richness (\#) & 18.83 & 7.38 & 18.00 & 7.00 & 39.00 \\
\hline & & Vegetation cover $(\%)$ & 97.26 & 25.39 & 94.00 & 60.00 & 166.00 \\
\hline & & Tallest vegetation $(\mathrm{cm})$ & 168.10 & 34.80 & 180.0 & 58.00 & 220.00 \\
\hline
\end{tabular}

Variables produced through canopy height models (CHM) created from UAV drone surface readings are in meters

using lidR's function grid_canopy, which builds a Digital Surface Model (DSM) on the ground normalized pointcloud by calculating the height above ground of any point that is not a ground point. Normalizing the point cloud before applying grid_canopy spares the need of calculating a Digital Terrain Model (DTM, ground topography) first. The CHM expresses point height above ground in meters and was calculated at $2.5 \mathrm{~cm}$ resolution, which then allows the analysis and digital measurements of plants and objects within the study area. We hypothesized that the CHM at each fine spatial scale could represent structural and functional vegetation characteristics of gardens assuming all vegetation contributes to vegetation structure and function. To avoid empty pixels (or 'pits') giving false readings within the CHM, a subcircle of 0.2 was applied to each point return (Khosravipour et al. 2014). CHMs were converted into rasters and clipped to: (1) the spatial polygons of the garden to remove data from outside the garden boundaries; (2) the spatial polygons of the individual plots that we measured; (3) a minimum value of $0.10 \mathrm{~m}$ to limit the influence of low elevation ground points $(0 \mathrm{~m})$ from pathways and non-vegetated areas outside of plots; and (4) a maximum value of $3.5 \mathrm{~m}$ to remove outlier data from built structures and larger trees surrounding and within the garden along the perimeter to focus only on the vegetation planted within plots managed by gardeners. A detailed description of flight and processing parameters, photogrammetry workflow and software settings can be found in the appendix (Table 1; Online Appendix 2).

\section{Analysis}

To determine how indicators of vegetation-related ecosystem structure and function vary in gardens at the two different spatial scales, we calculated summary statistics for in-field measurements of garden vegetation (species richness, herbaceous vegetation cover, vegetation height) and for the UAV-derived CHM for each garden and for each garden plot (Table 1). To evaluate the relationship between UAV canopy height data and field measurements of plant species richness, vegetation height, and herbaceous vegetation cover we built generalized linear models (GLMs) to test how 


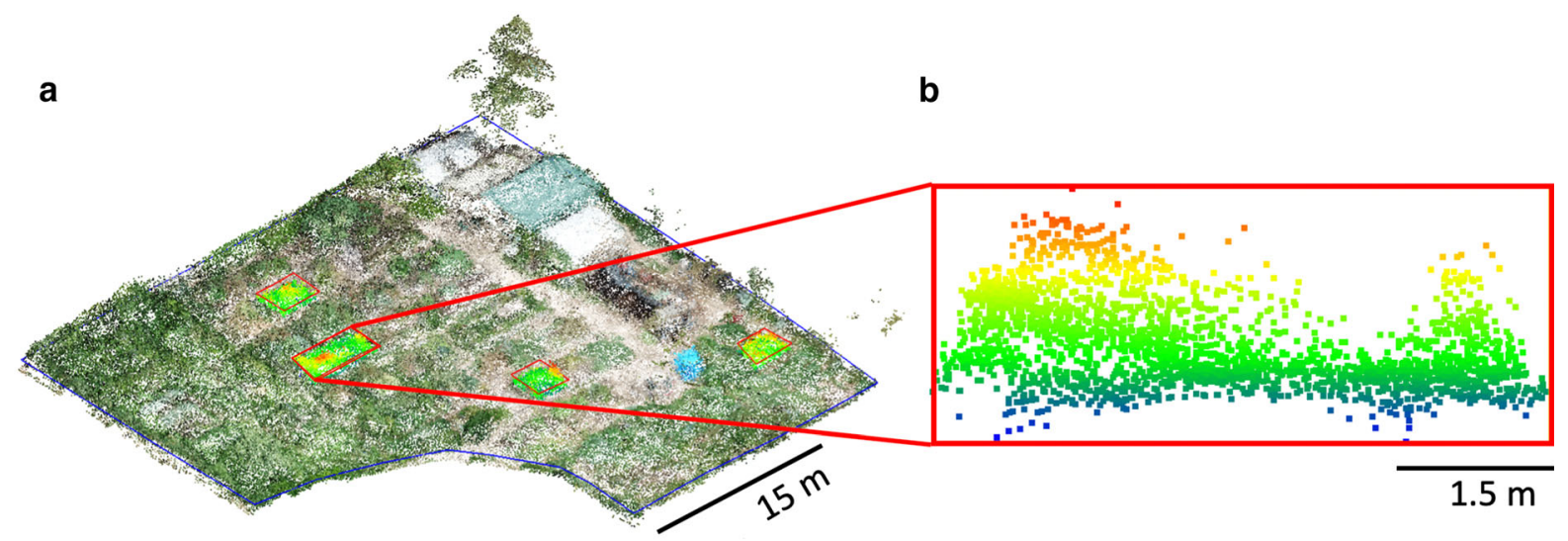

c

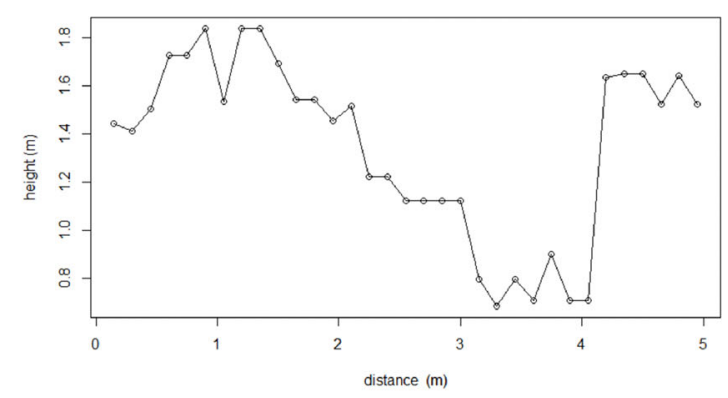

Center length width profile

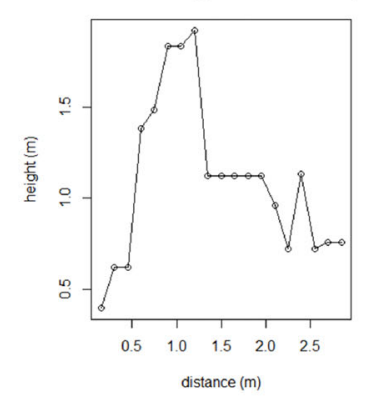

Fig. 2 The normalized point cloud at the garden scale (a) and the plot scale (b) contains information of each pixel's height above the ground. We provide an example of a plot's (here of Fig. 3c) center length height profile and width profile in meters (c)

well CHMs predict field observation data at the garden and plot scale, informed by hypothesized relationships.

We tested three relationships between field measurements and canopy height data at each scale: (1) measured plant species richness explained by mean $\mathrm{CHM}$ and variation in CHM values (standard deviation; SD); (2) measured herbaceous vegetation cover (\%) explained by CHM vegetation cover (\% total $>0.1 \mathrm{~m}$ ); and (3) measured heights of tallest nonwoody vegetation explained by mean, variation and maximum CHM values corrected for the additional height above ground from raised garden beds. Here we hypothesized that plant species richness would best correlate with variation (SD) in CHM; vegetation cover would correlate with cover estimated from CHMs; and the height of the tallest vegetation would correlate with the maximum CHM. For the tallest vegetation height models, maximum values were only modeled for plot scale measures because nearly all maximum values at the garden scale were $3.5 \mathrm{~m}$ due to the set threshold for the CHMs. The plant species richness GLM was fit with a Poisson distribution; herbaceous vegetation cover models and tallest vegetation models were fit with a Gaussian distribution. To account for sampling areas for species richness, plot size $\left(\mathrm{m}^{2}\right)$ was included as an offset term in the plot-scale models for species richness, and garden size $\left(\mathrm{m}^{2}\right)$ was included as an offset term in the garden-scale models. An offset term is a known component of the linear predictor variable that requires no coefficient (McCullagh and Nelder 1989). Significance of the explanatory variable (CHM values) was identified at $P \leq 0.05$. Model fit for each model was estimated using Akaike's Information Criteria (AICc) relative to a null model, where lower AICc values indicate a better model fit (Burnham and Anderson 2002). Analyses were performed in R (R Development Core Team 2016). 
a

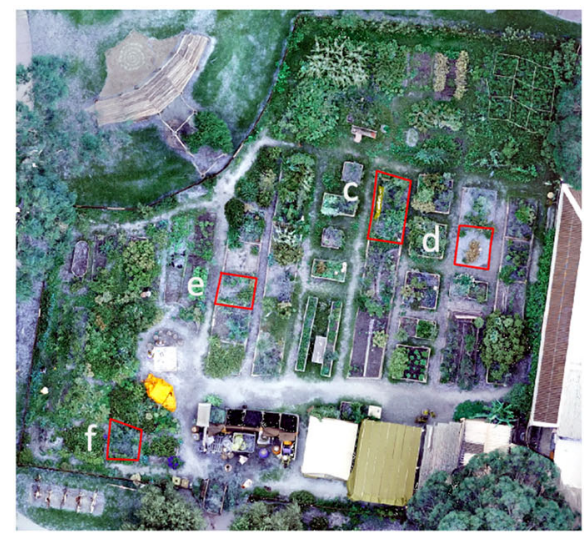

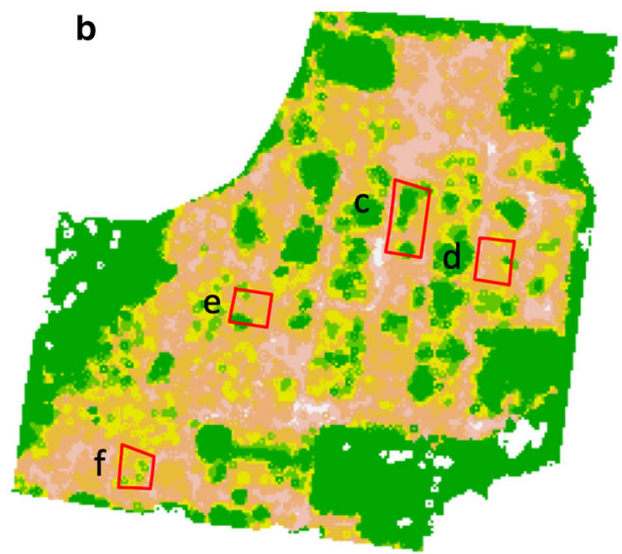

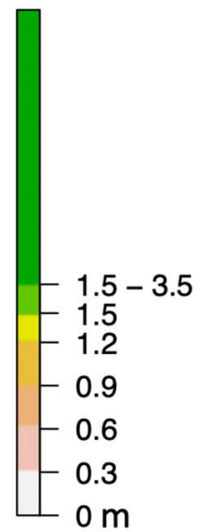

C

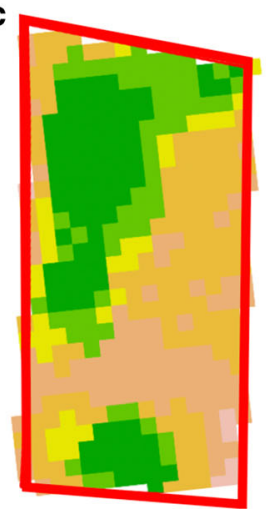

d

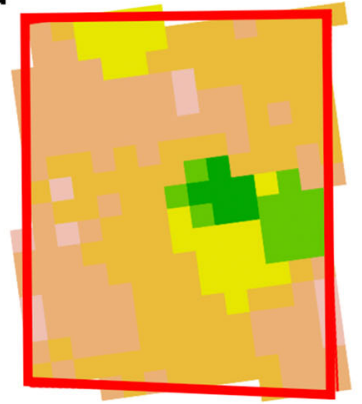

e

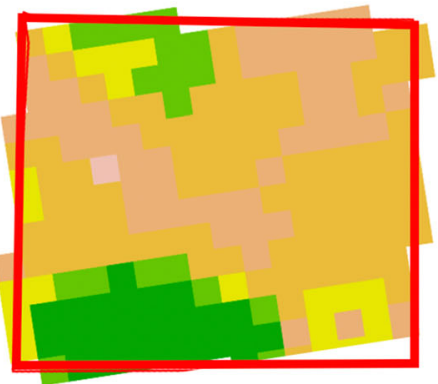

f

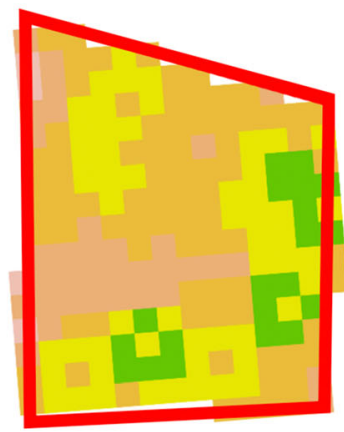

Fig. 3 Orthomosaic aerial images (a) of each urban community garden derived from a 3D point cloud model (Fig. 2a) was processed into a canopy height model (CHM in meters; b). Data

\section{Results}

Plant species richness, vegetation height, and herbaceous vegetation cover measured in the field varied among the garden plots and the community gardens (Figs. 2 and 3; Table 1). UAV imagery-derived CHM measurements also varied among garden plots and community gardens (Table 1). Ecosystem structure measures varied between gardens and plots: mean vegetation height was similar, with a majority of the gardens and plots having vegetation that averaged around $1 \mathrm{~m}$ in height. At the garden scale all gardens had vegetation that was over $3 \mathrm{~m}$, but the average maximum height within plots was around $2 \mathrm{~m}$. Gardens also had a lot of low to no vegetation ( $0 \mathrm{~m}$ in height). At the individual plot scale, most plots exhibited at least some low vegetation under $0.5 \mathrm{~m}$. Indicators of ecosystem function differed between garden and plot scale. Mean plant species were clipped to the border of the individual garden plots that were surveyed within each garden $(\mathbf{c}-\mathbf{f})$ for further analysis of the separate spatial scales considered in this study

richness observed at the garden scale (across the gardens) was 32 species. Mean plant species richness observed within garden plots was approximately 19 species. There was similar high variability among gardens and plots ( \pm 8 species). The mean vegetation cover observed tended to be higher for measures within plots than measures taken at the garden scale.

UAV surface readings of garden and plot vegetation related to some measures of garden vegetation observed in the field (Fig. 4; Table 2). Mean and variation in $\mathrm{CHM}$ values of garden vegetation correlated to observed plant species richness in gardens at both the garden and plot scale, but the direction of the relationship was scaledependent and indicated a reverse scale relationship. Here plant species richness significantly increased at the plot scale and decreased at the garden scale with higher mean CHM values (Fig. 4a,b). Plant species richness significantly decreased with greater variation in CHM 


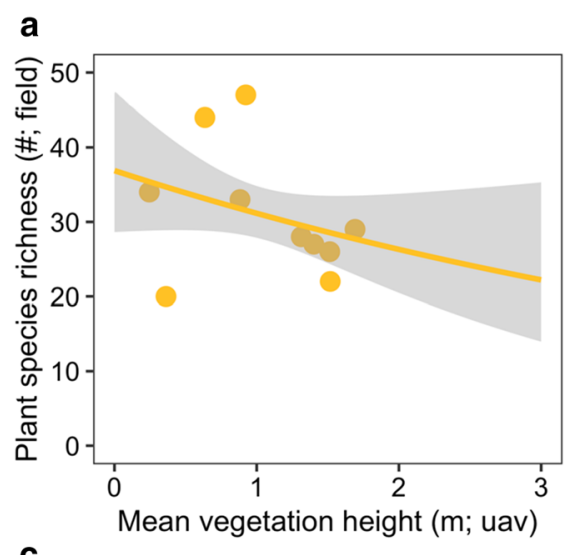

b
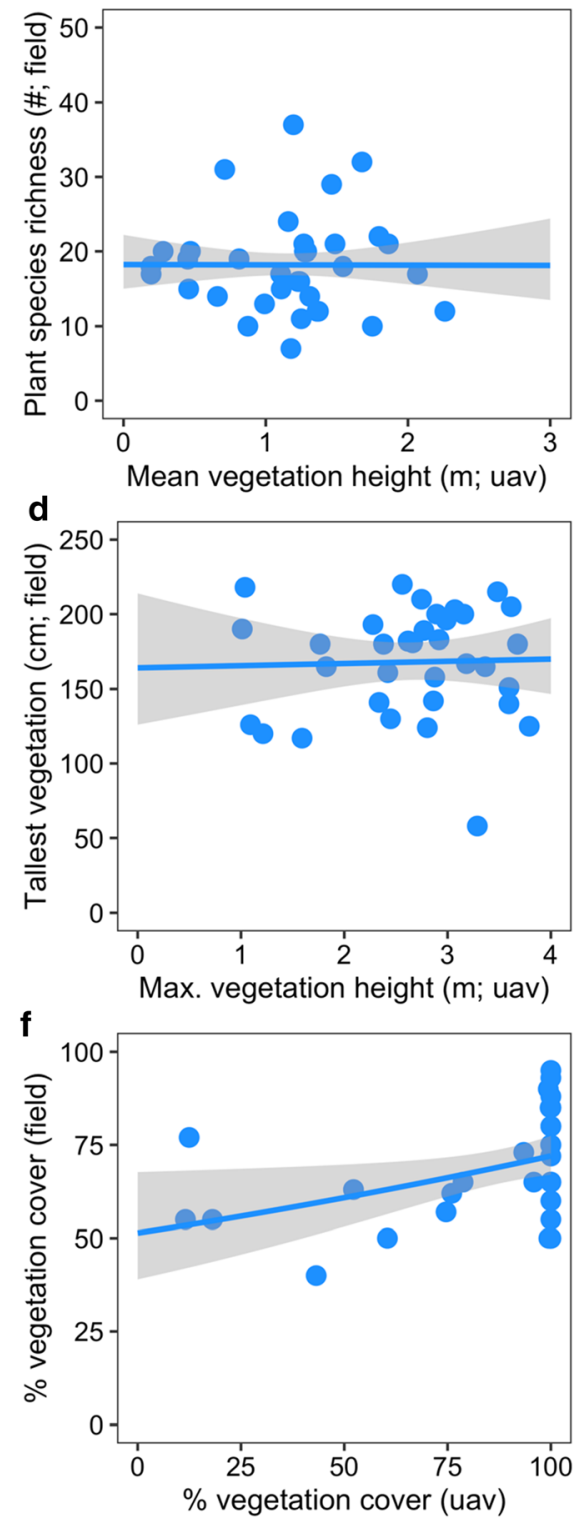

Each point represents a garden or a single garden plot., with data presented in meters $(\mathrm{m})$ for a-d. Line fit and gray shading represent the GLM fitted with a Poisson or Gaussian error distribution for each respective analysis (see methods)

\section{Discussion}

Vegetation in urban community gardens varies within and across gardens at different spatial scales with implications for agroecosystem function, biodiversity conservation, and ecosystem service provisioning across urban landscapes. Yet, like many urban 
Table 2 Results of the generalized linear models (GLMs) of the vegetation properties measured in the field by researchers at the garden scale (a) and at the scale of the gardener's plot (b) as the response variables

\begin{tabular}{|c|c|c|c|c|c|c|c|}
\hline Scale & Model & Predictor & Coef. & SE & $\mathrm{t}$ & $p$ & dAICc \\
\hline \multirow[t]{12}{*}{ (a) Garden (1 m) } & \multirow[t]{2}{*}{ Plant sp richness $\sim$ mean $\mathrm{CHM}$} & Intercept & 3.73 & 0.00 & 1305.79 & $<0.001$ & \multirow[t]{2}{*}{-100.50} \\
\hline & & mean CHM & -0.13 & 0.00 & -43.84 & $<0.001$ & \\
\hline & \multirow{2}{*}{ Plant sp richness $\sim \mathrm{SD} \mathrm{CHM}$} & Intercept & 3.91 & 0.01 & 598.02 & $<0.001$ & \multirow[t]{2}{*}{-2154.30} \\
\hline & & SD CHM & -0.49 & 0.01 & -46.33 & $<0.001$ & \\
\hline & \multirow[t]{2}{*}{$\%$ Herbaceous cover $\sim \% \mathrm{CHM}$ cover } & (Intercept) & 51.57 & 7.97 & 6.47 & $<0.001$ & \multirow[t]{2}{*}{-2.75} \\
\hline & & $\% \mathrm{CHM}$ cover & 0.20 & 0.09 & 2.29 & 0.03 & \\
\hline & \multirow[t]{2}{*}{ Tallest vegetation $\sim$ mean $\mathrm{CHM}$} & Intercept & 73.29 & 13.74 & 5.34 & $<0.001$ & \multirow[t]{2}{*}{4.20} \\
\hline & & Mean CHM & 3.67 & 14.10 & 0.26 & 0.80 & \\
\hline & \multirow[t]{2}{*}{ Tallest vegetation $\sim \mathrm{SD} \mathrm{CHM}$} & Intercept & 70.47 & 31.12 & 2.26 & 0.05 & \multirow[t]{2}{*}{4.24} \\
\hline & & SD CHM & 9.87 & 49.45 & 0.20 & 0.85 & \\
\hline & \multirow[t]{2}{*}{ Tallest vegetation $\sim \max . \mathrm{CHM}$} & Intercept & -33.47 & 366.03 & -0.09 & 0.93 & \multirow[t]{2}{*}{4.17} \\
\hline & & Max CHM & 31.87 & 105.99 & 0.30 & 0.77 & \\
\hline \multirow[t]{12}{*}{ (b) Plot $(0.2 \mathrm{~m})$} & \multirow[t]{2}{*}{ Plant sp richness $\sim$ mean $\mathrm{CHM}$} & Intercept & -35.58 & 0.09 & -383.90 & $<0.001$ & \multirow[t]{2}{*}{-3883.52} \\
\hline & & Mean CHM & 7.83 & 0.07 & 118.50 & $<0.001$ & \\
\hline & \multirow[t]{2}{*}{ Plant sp richness $\sim \mathrm{SD}$ CHM } & Intercept & -15.09 & 0.17 & -87.89 & $<0.001$ & \multirow[t]{2}{*}{-1945.52} \\
\hline & & SD CHM & -25.86 & 0.36 & -71.70 & $<0.001$ & \\
\hline & \multirow[t]{2}{*}{$\%$ Herbaceous cover $\sim \% \mathrm{CHM}$ cover } & Intercept & -1906.92 & 2569.95 & -0.74 & 0.48 & \multirow[t]{2}{*}{-4.28} \\
\hline & & $\% \mathrm{CHM}$ cover & -1.17 & 29.29 & -0.04 & 0.97 & \\
\hline & \multirow[t]{2}{*}{ Tallest vegetation $\sim$ mean $\mathrm{CHM}$} & Intercept & 148.62 & 14.11 & 10.53 & $<0.001$ & \multirow[t]{2}{*}{2.34} \\
\hline & & Mean CHM & 2.65 & 10.57 & 0.25 & 0.80 & \\
\hline & \multirow[t]{2}{*}{ Tallest vegetation $\sim \mathrm{SD} \mathrm{CHM}$} & Intercept & 154.26 & 17.75 & 8.69 & $<0.001$ & \multirow[t]{2}{*}{2.39} \\
\hline & & SD CHM & -5.42 & 36.36 & -0.15 & 0.88 & \\
\hline & \multirow[t]{2}{*}{ Tallest vegetation $\sim \max . \mathrm{CHM}$} & Intercept & 152.50 & 22.48 & 6.78 & $<0.001$ & \multirow[t]{2}{*}{2.41} \\
\hline & & Max CHM & -0.27 & 8.15 & -0.03 & 0.97 & \\
\hline
\end{tabular}

Explanatory variables (predictors) are measurements derived from canopy height models (CHMs) created from UAV drone imagery. Spatial scale of the data for the gardens was one meter, and for garden plots was $0.2 \mathrm{~m}$

dAICc delta AICc, SD standard deviation, SE standard error

ecosystems, changes in vegetation species diversity, cover, or height can be difficult to measure due to site access, time limitations, and fast vegetation turnover. In this study, we asked how garden vegetation form (plant species diversity, cover) and structure (height) as indicators of important ecosystem functions (e.g. pollination, pest control, nutrient cycling) vary at two relevant spatial scales in gardens, and we utilized new technologies in combination with traditional field methods common in urban ecology to help us answer this question. We measured variation in garden vegetation using remote sensing and human observation, and compared observations between methods to inform relationships between new and traditional methods in urban ecology, and to guide future research.

We found that garden plots and garden habitats vary in vegetation form and structure as indicated by the number of plant species, vegetation height and percent cover. This has important implications for vegetationrelated pest control, pollination, or climate regulation services in gardens relevant to food provision (Lin et al. 2015). In comparing remotely sensed imagery and human observation, we found reverse-scale relationships between measures at the individual garden plot scale versus the garden habitat scale: specifically, the relationship for the richness of plant species at each scale. Our findings show that fine-scale variation of vegetation within garden plots contribute much to the overall ecological heterogeneity within garden habitats and suggest that interpretations of vegetation patterns and related ecosystem function are scale- and methodology dependent. Furthermore, both new technologies and traditional field methods in urban landscape ecology need to be applied together to answer more complete ecological questions. Some ecological 
questions may be more readily answered by remote sensing data, while some may require more thorough and detailed in-field measurements or detailed ground truthing before a model can be derived. We explore the study's main findings: (1) changes in garden vegetation in relation to spatial scale with implications for ecosystem function and management; (2) lessons on relationships between new and traditional methods for vegetation assessments; and (3) the potential of UAVs in urban landscape vegetation mapping particularly for hard to survey sites.

The spatial scale of variation in vegetation and its importance

Changes in land use within and across habitats shapes local to landscape-scale patterns for biodiversity conservation and ecological function (Turner et al. 2013). More spatially and ecologically heterogeneous landscapes often support more diversity and greater ecosystem functions than those that are more homogenous (Dunning et al. 1992; Fahrig 2003), as has been shown in natural (Gustafson 1998; Turner et al. 2013) and agricultural landscapes (Tscharntke et al. 2012). In urban community gardens, a species diverse land use type, the spatial scale of changes in vegetation structural and compositional features is of special importance because ecosystem functions are scale dependent (Andersson et al. 2015). For example, plotscale management of floral distributions may influence pollinator communities to affect pollination services (Plascencia and Philpott 2017), whereas habitat-scale variables, including tree abundance and canopy cover, may affect temperature variability or carbon sequestration services (Andersson et al. 2015).

Urban garden plots managed by individual gardeners contain high numbers of plant populations within relatively small areas (Colding et al. 2006) —in this study, 39 plant species were observed in one plot with an average plot size of $14 \mathrm{~m}^{2}$. This value was nearly close to the overall species diversity captured in the random field sampling of the garden-scale plant species. The results support the idea that fine-scale processes occurring through individual gardener management can create interesting variation in vegetation form and structure between plots, as shown by the CHMs. Although this variation in vegetation presumably scales up to the garden landscape, our findings indicate that evaluating vegetation characteristics at the basic unit of the individual plot is an insightful measure of structural and functional differences among garden plots. Changes in vegetation form and structure can also have important implications for the ability of gardens to support ecosystem services related to food production because ecosystem service providers (e.g. insect pollinators or natural enemies) are strongly influenced by habitat vegetation characteristics in gardens for food (nectar, prey) or shelter. Thus, it is important to focus on the management of individual garden plots to best understand ecological applications regarding managing habitats for ecosystem services.

Plant species richness and vegetation cover at the plot scale related to CHM values, suggesting that at this scale UAV technologies can adequately predict species richness as we discuss below. An assessment within garden plots should produce more detailed data on vegetation, and we show that this can relate to UAV imagery values at this scale. However, the reversescale relation in species richness within garden plots (positive relationship) versus within the garden (negative relationship) indicate a divergent scale-dependent association between spatial imagery and some garden features, and provides an example of why scale matters in landscape ecology research. Simpson's Paradox describes such reverse-scale patterns (Blyth 1972): statistical relationships at the aggregated scale yield different conclusions than the relationships within the individual. The sum of parts tells a different story than the individual parts do themselves. Biodiversity studies using remote sensing in natural landscapes similarly illustrate that fine-scale variability and information rapidly decreases with increasing sampling scale (Cavender-Bares et al. 2017; Wang et al. 2018). A closer examination of an individual plot, generally consisting of mostly herbaceous nonwoody plants, finds that mean CHM values can provide a relatively good assessment of basic vegetation metrics, specifically for vegetation function (species richness, cover). In sum, these findings suggests that if the process of interest is at the garden plot scale (e.g. ecosystem functioning), analyzing the disaggregated data (i.e. of individuals) rather than the aggregated data is better to reduce information loss (i.e. individual variation) and other aggregation problems (Clark et al. 2011). Based on these findings, we recommend that species richness is an insightful measure of ecosystem function within gardens, but 
importantly should be considered at a meaningful spatial scale. Here, a meaningful spatial scale is the scale of individual's management (a gardener's).

Mapping variation in garden vegetation:

relationships between new and traditional methods

We used low-cost and accessible UAV technology paired with human field surveys to together answer questions about how vegetation form and structure changes at various spatial scales within gardens, and how new and traditional methods in urban ecology are related. Home and community gardens in cities can be difficult to access but are important for supporting many plant and invertebrate species (Colding et al. 2006). Higher plant species richness and vegetation cover within plots was positively predicted by some UAV-derived imagery values. Yet surprisingly and counter to our predictions, greater variation in CHM values (here, the standard deviation (SD)) correlated negatively with species richness and vegetation height was not predicted by UAV imagery at either plot or garden scale. The negative relationship between variation in $\mathrm{CHM}$ and species richness suggests that gardeners may have highly diverse plots of species of similar heights. No relationship between vegetation height and CHM values may be explained by our field sampling method that was limited to measuring only the height of the tallest vegetation within the plot, and to a subset of garden plots. Furthermore, a sensor may not be able to capture vegetation within a garden plot depending on the size and structure of the plant (e.g., tall but thin vegetation). Such surprising relationships provide valuable insight for future research. A more complete field measurement of vegetation height within a plot, measuring the volume (height $\times$ area) of multiple layers of vegetation representing different functional groups could provide ground data that better relate to remote sensing images. In addition, the dynamic nature of these systems through vegetation management may influence our results and generally has implications for the reproducibility of such studies in urban environments. However, it is not possible to return to gardens later on to collect additional data because these gardens (and most community gardens) are highly seasonal, and vary from season to season in ownership. Consequently, preference in planted species and vegetation features likely varies. This might be a key constraint of data collection in urban gardens and limits the time of collecting and confirming data to a few weeks per year.

We highlight benefits and drawbacks on the use of the UAV technology and combined field methods to aid in answering our research question. Logistical feats can hinder the ability to understand the role of gardens for biodiversity conservation and urban macro-ecosystem function (Guitart et al. 2012). Even "quick" in-field assessments of the system require extensive time for high sample sizes and ecological knowledge, and the social-ecological turnover within these systems across the growing season (in plants, in people) suggests that multiple and repeated assessments over time are essential to make strong conclusions. Such temporal processes as well as too few infield sampling points, could provide further explanations for the lack of relationships between UAV imagery and garden-scale height measurements. Furthermore, the 'randomness' in plot composition due to differences in gardener planting preferences (Egerer et al. 2019) may make it difficult to derive relationships. A plot can be so individually different from another that simple measures of height or cover cannot detect or relate to variables such as species richness. For example, plots with high species richness could have vegetation cover and structure exactly like one that has only a couple of species. Thus, even if UAV imagery produces accurate and precise readings that can reduce field measurement effort, it might still not be useful in predicting further relationships. Urban community gardens present excellent systems to test new technologies like UAVs because, in comparison to residential systems, community gardens often only require city and garden management cooperation to access and quickly assess the relatively small landscape (though this has its own challenges, see (Guitart et al. 2012; Pollard et al. 2017)). UAVs may be useful for ecosystem assessments at various spatial scales given time, labor and funding constraints. In our study, even our field assessments by two to three researchers took 3-4 h per garden to complete, and data entry and plant identification in the lab took 3 weeks. In contrast, UAV data collection took 5-10 min in the field, 1 day to correct and compile, and takes approximately a week to prepare data (here, of ten entire gardens) for analysis depending on the workflow and mapping software fluency. 
Applying and developing methods together

Thus, what do we have to change from the ground, but also from the sky, to further methodological advancements utilizing new technologies in urban landscape ecology research? The lack of some relationships in measurements from UAV and field methods suggest that field methods must develop with new technologies to be able to provide accurate reference ground data to confirm data taken from the sky. For example, here, field assessments could collect multiple vegetation height measurements in a grid in each garden plot. With this data, we could interpolate between height points to quantify, for example plot vegetation volume estimates that are relatable to CHMs produced from UAV imagery. More height measurements in the field will allow for better relationships to species richness because the different morphological features expressed by garden plants can be used for species differentiation. Field methods that move beyond common measurements are necessary to provide quality reference ground data for UAV assessments. Provided such field data, new technologies like UAVs may provide a cost- and time-effective alternative for traditional baseline estimates of vegetation characteristics with implications for ecosystem function and habitat management in urban landscapes.

Spatial scale is also key to the accuracy and application of remote sensing technology ( $\mathrm{Lu}$ and $\mathrm{He}$ 2018; Wang et al. 2018) and should be carefully considered in research methodology. In our study this is supported by the reverse-scale relationship between methodologies (UAV, human observation) and the lack of strong relationships observed between UAV and most human observations of vegetation at the garden scale. Previous studies have found that spatial scale correction is necessary to fix the misclassification of land use types by UAVs in images of urban tree populations (Feng et al. 2015) and scale analysis should be a component to the methodological workflow (Cavender-Bares et al. 2017; Wang et al. 2018). Indeed, surface models produced from UAV surveys are very sensitive to systematic error (James and Robson 2014), and corroborating remote sensing with on the ground assessments is still important for assessing correlations and predictability (Peña et al. 2013; Wang et al. 2018). As is using other correction techniques such as implementing ground control points and bundle adjustments to mitigate systematic errors (James et al. 2017). Urban gardens are also dynamic systems in which plants can be short lived or quickly modified, and we emphasize the advantage of being able to carry out ground sampling and UAV data collection in unison on the same day, saving time and effort. Our analysis is limited to the garden plots in which we measured all vegetation and plot characteristics (thus assuming all plants play some functional role), and limited to the ground resolution restricted by the infrastructure features of urban environments and UAV government regulations. Yet we suggest that detailed interpretation of garden CHMs paired with infield researcher observation may best describe ecosystem structure and functioning depending on the research question. UAV technology may readily answer questions around basic vegetation species diversity and vegetation structural features of an ecosystem, but questions around relationships with other taxa or management of specific plant functional groups related to a single ecosystem service may require more detailed field measurements and adapted methods to answer due to lost temporal or spatial resolution.

This study is a glimpse into how high-spatial resolution imagery may be utilized for mapping the vegetation of private green spaces. Private green spaces make up more than $50 \%$ of all urban green space in many cities (Goddard et al. 2010), yet we have little to no access to these spaces. This is particularly true for backyards, which often have more plant richness and vegetation complexity (Daniels and Kirkpatrick 2006) but are much less visible (Locke et al. 2018) and accessible due to privacy concerns. Consequently, we know little about their ecology (Cook et al. 2012). A system that can assess and account for plant species richness and vegetation structural characteristics across a cityscape using high resolution remote sensing (provided site permission) could be a means to better understand the ecology of residential gardens both within front and back yards, and their role in supporting urban ecosystem functions and ecosystem services.

\section{Conclusion}

Gardens are diverse in plant species and complex in vegetation structure. Furthermore, gardens harbor many important ecosystem service providers within 
them. Understanding the variation in vegetation within gardens is relevant to biodiversity conservation and sustainability initiatives, but in urban landscapes it can be logistically difficult to comprehensively assess the vegetation within these ecosystems. Methodological advancements harnessing new technologies are increasingly used in urban landscape ecology research, but it is still unclear how these relate to basic and traditional field methods used by most urban ecologists. Our work furthers both interpretations of variation in garden vegetation and methodological developments of new and traditional methods in urban ecology. We introduce two methods for vegetation assessments-traditional in-field surveys and new UAV technology - that can be utilized by urban ecologists, urban planners, and urban farmers alike. First, the findings prompt questions of spatial scale selection when using these technologies for meaningful analyses of heterogeneous systems. Remote sensing may lose resolution of plant species richness if the spatial scale is too large, which can shape conclusions about ecosystem functioning or management outcomes aimed at improving structural diversity. For researchers, we recommend that scale analyses in the context of the research question should be incorporated into the workflow of vegetation mapping, and must consider small spatial scales as shapers of variation and complexity in vegetation form and function. Second, our results highlight the importance of detailed ground surveys that move beyond traditional and common vegetation measurements to produce relatable data to new technologies. Yet UAV imagery may overlook important fine-scale functional attributes of urban ecosystems that field surveys may capture. For urban planners, depending on the objective and accessibility, UAV technology may provide new venues to better measure vegetation across the landscape to enhance and improve equitable ecosystem service provision. For urban farmers, using cheap technologies in combination with measurements within and knowledge of their plots could provide new pathways to manage structural and functional vegetation features that underlie agroecosystem functions and sustainable food production. To best understand ecological outcomes, local fine-scale information and data from researchers and land managers can complement and improve ecosystem observations taken from the sky.
Acknowledgements Thank you to the following community gardens and gardeners for facilitating this research: Ashburton Community Garden, Balwyn Community Garden, Box Hill Community Garden, Essendon Community Garden, Flemington Community Garden, Hawthorn Riversdale Road Community Garden, Nunawading-Jolimont Community Garden, Nunawading-Slater Community Garden, Rushall Community Garden, and West Brunswick Community Garden and Food Forest. Thank you to: H-A. Tan and A. Singh for field research efforts; S. Andrusiak for plant identification; C Anton and J Suraci for assistance with data processing; and to the University of Melbourne-Burnley, specifically S. Livesley and N Williams for hosting the research. Funding for this project was provided by: the Clean Air and Urban Landscapes hub of the Australia Government's National Environmental Science Programme, which supports D.K. (\# DE170100208); and a US National Science Foundation Graduate Research Opportunities Worldwide Fellowship to M.H.E. (\#2016-174835). We acknowledge support by the German Research Foundation and the Open Access Publication Fund of TU Berlin provided through Projekt DEAL. Findings and conclusions expressed in this material are those of the author and do not necessarily reflect the views of the funding organizations.

Authors contribution All authors conceived of the study. MHE and BW carried out the data collection (field surveys, UAV surveys). MHE, BW, KZ analyzed the data. MHE drafted the manuscript with contributions from all authors.

Funding Open access funding provided by Projekt DEAL.

Data accessibility The datasets supporting this article are available upon reasonable request.

\section{Compliance with ethical statement}

Conflict of interest We have no competing interests to declare.

Ethical statement All sites were sampled and surveyed with written or verbal permission from land managers.

Open Access This article is licensed under a Creative Commons Attribution 4.0 International License, which permits use, sharing, adaptation, distribution and reproduction in any medium or format, as long as you give appropriate credit to the original author(s) and the source, provide a link to the Creative Commons licence, and indicate if changes were made. The images or other third party material in this article are included in the article's Creative Commons licence, unless indicated otherwise in a credit line to the material. If material is not included in the article's Creative Commons licence and your intended use is not permitted by statutory regulation or exceeds the permitted use, you will need to obtain permission directly from the copyright holder. To view a copy of this licence, visit http://creativecommons.org/licenses/by/4.0/. 


\section{References}

Alvey AA (2006) Promoting and preserving biodiversity in the urban forest. Urban For Urban Green 5:195-201

Anderson CB (2018) Biodiversity monitoring, earth observations and the ecology of scale. Ecol Lett 21:1572-1585

Andersson E, Barthel S, Ahrné K (2007) Measuring socialecological dynamics behind the generation of ecosystem services. Ecol Appl 17:1267-1278

Andersson E, McPhearson T, Kremer P, Gomez-Baggethun E, Haase D, Tuvendal M, Wurster D (2015) Scale and context dependence of ecosystem service providing units. Ecosyst Serv. https://doi.org/10.1016/j.ecoser.2014.08.001

Anderson EC, Egerer MH, Fouch N, Clarke M, Davidson M (2019) Comparing community garden typologies of Baltimore, Chicago, and New York City (USA) to understand potential implications for socio-ecological services. Urban Ecosyst 22:671-681

Bell S, Fox-Kämper R, Keshavarz N, Benson M, Caputo S, Noori S, Voigt A (2016) Urban allotment gardens in Europe. Taylor \& Francis, Routledge

Bivand R, Keitt T, Rowlingson B (2018) Bindings for the "Geospatial" data abstraction library [R package rgdal version 1.4-3]

Blyth CR (1972) On Simpson's paradox and the sure-thing principle. J Am Stat Assoc 67:364-366

Burnham KP, Anderson DR (2002) Model selection and multimodel inference: a practical information-theoretic approach. Springer, New York

Cavender-Bares J, Gamon JA, Hobbie SE, Madritch MD, Meireles JE, Schweiger AK, Townsend PA (2017) Harnessing plant spectra to integrate the biodiversity sciences across biological and spatial scales. Am J Bot 104:966-969

Civil Aviation Safety Authority (2019) Flying in public spaces. In: Rules Regul. https://www.casa.gov.au/drones/rules/ public-spaces. Accessed 19 Nov 2019

Clark JS, Bell DM, Hersh MH, Kwit MC, Moran E, Salk C, Stine A, Valle D, Zhu K (2011) Individual-scale variation, species-scale differences: inference needed to understand diversity. Ecol Lett 14:1273-1287

Colding J, Lundberg J, Folke C (2006) Incorporating green-area user groups in urban ecosystem management. Ambio 35:237-244

Cook EM, Hall SJ, Larson KL (2012) Residential landscapes as social-ecological systems: a synthesis of multi-scalar interactions between people and their home environment. Urban Ecosyst 15:19-52

Cunliffe AM, Brazier RE, Anderson K (2016) Ultra-fine grain landscape-scale quantification of dryland vegetation structure with drone-acquired structure-from-motion photogrammetry. Remote Sens Environ 183:129-143

Daniels GD, Kirkpatrick JB (2006) Does variation in garden characteristics influence the conservation of birds in suburbia? Biol Conserv 133:326-335

Drescher AW, Holmer RJ, Iaquinta DL (2006) Urban homegardens and allotment gardens for sustainable livelihoods: management strategies and institutional environments. Tropical homegardens. Springer, Dordrecht, pp 317-338

Duffy JP, Pratt L, Anderson K, Land PE, Shutler JD (2018) Spatial assessment of intertidal seagrass meadows using optical imaging systems and a lightweight drone. Estuar Coast Shelf Sci 200:169-180

Dunning JB, Danielson BJ, Pulliam HR (1992) Ecological processes that affect populations in complex landscapes. Oikos 65:169-175

Egerer MH, Bichier P, Philpott SM (2016) Landscape and local habitat correlates of lady beetle abundance and species richness in urban agriculture. Ann Entomol Soc Am 110:97-103

Egerer MH, Lin BB, Threlfall CG, Kendal D (2019) Temperature variability influences urban garden plant richness and gardener water use behavior, but not planting decisions. Sci Total Environ 646:111-120

Elmqvist T, Gómez-Baggethun E, Langemeyer J (2016) Ecosystem services provided by urban green infrastructure. In: Potschin M, Haines-Young R, Fish R, Turner RK (eds) Routledge handbook of ecosystem services. Routledge, New York, pp 452-468

Erena M, Portillo D, Fernández L (2016) Configuration and specifications of an unmanned aerial vehicle for precision agriculture. ISPRS - Int Arch Photogramm Remote Sens Spat Inf Sci XXIII ISPRS Congr. https://doi.org/10.5194/ isprsarchives-xli-b1-809-2016

Fahrig L (2003) Effects of habitat fragmentation on biodiversity. Annu Rev Ecol Syst 34:487-515

Feng Q, Liu J, Gong J (2015) UAV remote sensing for urban vegetation mapping using random forest and texture analysis. Remote Sens 7:1074-1094

Flynn DFB, Gogol-Prokurat M, Nogeire T, Molinari N, Richers BT, Lin BB, Simpson N, Mayfield MM, DeClerck F (2009) Loss of functional diversity under land use intensification across multiple taxa. Ecol Lett 12:22-33

Foley JA, Defries R, Asner GP, Barford C, Bonan G, Carpenter SR, Chapin FS, Coe MT, Daily GC, Gibbs HK, Helkowski JH, Holloway T, Howard E, Kucharik CJ, Monfreda C, Patz JA, Prentice IC, Ramankutty N, Snyder PK (2005) Global consequences of land use. Science 309:570-574

Gaitani N, Burud I, Thiis T, Santamouris M (2017) Aerial survey and in situ measurements of materials and vegetation in the urban fabric. Proc Eng 180:1335-1344

Gámez-Virués S, Perović DJ, Gossner MM, Börschig C, Blüthgen N, de Jong H, Simons NK, Klein A, Krauss J, Maier G, Scherber C, Steckel J, Rothenwöhrer C, SteffanDewenter I, Weiner CN, Weisser W, Werner M, Tscharntke T, Westphal C (2015) Landscape simplification filters species traits and drives biotic homogenization. Nat Commun 6:8568

Goddard MA, Dougill AJ, Benton TG (2010) Scaling up from gardens: biodiversity conservation in urban environments. Trends Ecol Evol 25:90-98

Goodbody T, Coops N, Hermosilla T, Tompalski P, Pelletier G (2018) Vegetation phenology driving error variation in digital aerial photogrammetrically derived terrain models. Remote Sens 10:1554

Guitart D, Pickering C, Byrne J (2012) Past results and future directions in urban community gardens research. Urban For Urban Green 11:364-373

Gustafson EJ (1998) Quantifying landscape spatial pattern: what is the state of the art? Ecosystems 1:143-156

Herrero-Huerta M, Felipe-García B, Belmar-Lizarán S, Hernández-López $\mathrm{D}$, Rodríguez-Gonzálvez $\mathrm{P}$, González- 
Aguilera D (2016) Dense Canopy Height Model from a low-cost photogrammetric platform and LiDAR data. Trees Struct Funct 30:1287-1301

Hijmans RJ (2015) Geographic data analysis and modeling [R package raster version 2.6-7]

Hooper DU, Chapin FS III, Ewel JJ (2005) Effects of biodiversity on ecosystem functioning: a consensus of current knowledge. Ecol Monogr 75:3-35

Hooper DU, Vitousek PM (1997) The effects of plant composition and diversity on ecosystem processes. Science 277:1302-1305

Hostetler M, Holling C (2000) Detecting the scales at which birds respond to structure in urban landscapes. Urban Ecosyst 4:25-54

James MR, Robson S (2014) Mitigating systematic error in topographic models derived from UAV and ground-based image networks. Earth Surf Process Landforms 39:1413-1420

James MR, Robson S, d'Oleire-Oltmanns S, Niethammer U (2017) Optimising UAV topographic surveys processed with structure-from-motion: ground control quality, quantity and bundle adjustment. Geomorphology 280:51-66

Khosravipour A, Skidmore AK, Isenburg M, Wang T, Hussin YA (2014) Generating pit-free canopy height models from airborne lidar. Photogramm Eng Remote Sens 80:863-872

Knop EVA (2016) Biotic homogenization of three insect groups due to urbanization. Glob Change Biol 22:228-236

Koh LP, Wich SA (2012) Dawn of drone ecology: low-cost autonomous aerial vehicles for conservation. Trop Conserv Sci 5:121-132

Langemeyer J, Camps-Calvet M, Calvet-Mir L, Barthel S, Gómez-Baggethun E (2018) Stewardship of urban ecosystem services: understanding the value(s) of urban gardens in Barcelona. Landsc Urban Plan. https://doi.org/ 10.1016/j.landurbplan.2017.09.013

Lin BB, Egerer M (2017) Urban agriculture: an opportunity for biodiversity and food provision in urban landscapes. In: Ossola A, Niemelä J (eds) Urban biodiversity: from research to practice. Taylor \& Francis/Routledge, London

Lin BB, Fuller RA (2013) Sharing or sparing? How should we grow the world's cities? J Appl Ecol. https://doi.org/10. 1111/1365-2664.12118

Lin BB, Philpott SM, Jha S (2015) The future of urban agriculture and biodiversity-ecosystem services: challenges and next steps. Basic Appl Ecol 16:189-201

Lindenmayer D, Richard J, Montague- R, Alexandra J, Bennett A, Cale P, Cramer V, Driscoll D, Fischer J (2008) A checklist for ecological management of landscapes for conservation. Ecol Lett 11:78-91

Locke DH, Roy Chowdhury R, Grove JM, Martin DG, Goldman E, Rogan J, Groffman P (2018) Social norms, yard care, and the difference between front and back yard management: examining the landscape mullets concept on urban residential lands. Soc Nat Resour. https://doi.org/10.1080/ 08941920.2018.1481549

Loram A, Thompson K, Warren PH, Gaston KJ (2008) Urban domestic gardens (XII): the richness and composition of the flora in five UK cities. J Veg Sci 19:321-330
Lovell ST (2010) Multifunctional urban agriculture for sustainable land use planning in the United States. Sustainability 2:2499-2522

Lovell ST, Taylor JR (2013) Supplying urban ecosystem services through multifunctional green infrastructure in the United States. Landsc Ecol 28:1447-1463

Lu B, He Y (2018) Optimal spatial resolution of unmanned aerial vehicle (UAV)-acquired imagery for species classification in a heterogeneous grassland ecosystem. GIScience Remote Sens 55:205-220

Lu B, He Y, Liu HHT (2017) Mapping vegetation biophysical and biochemical properties using unmanned aerial vehicles-acquired imagery. Int J Remote Sens 39:1-23

Marvin DC, Koh LP, Lynam AJ et al (2016) Integrating technologies for scalable ecology and conservation. Glob Ecol Conserv 7:262-275

McCullagh P, Nelder JA (1989) Generalized linear models, 2nd edn. Chapman and Hall, London

McDonnell MJ, Hahs AK (2008) The use of gradient analysis studies in advancing our understanding of the ecology of urbanizing landscapes: current status and future directions. Landsc Ecol 23:1143-1155

McKinney ML (2006) Urbanization as a major cause of biotic homogenization. Biol Conserv 127:247-260

Mikhail EM, Bethel JS, McGlone JC (2001) Introduction to modern photogrammetry. Wiley, Chichester

Murfitt J, He Y, Yang J, Mui A, De Mille K (2016) Ash decline assessment in emerald ash borer infested natural forests using high spatial resolution images. Remote Sens 8:256

Näsi R, Honkavaara E, Lyytikäinen-Saarenmaa P, Blomqvist M, Litkey P, Hakala T, Viljanen N, Kantola T, Tanhuanpää T, Holopainen M (2015) Using UAV-based photogrammetry and hyperspectral imaging for mapping bark beetle damage at tree-level. Remote Sens 7:15467-15493

Ni W, Liu J, Zhang Z, Sun G, Yang A (2015) Evaluation of UAV-based forest inventory system compared with LiDAR data. In: International geoscience and remote sensing symposium (IGARSS). Institute of Electrical and Electronics Engineers Inc., pp 3874-3877

Ossola A, Locke D, Lin B, Minor E (2019) Greening in style: urban form, architecture and the structure of front and backyard vegetation. Landsc Urban Plan 185:141-157

Parker GG (1995) Structure and microclimate of forest canopies. Academic Press, San Diego, pp 73-106

Pau G, Fuchs F, Sklyar O, Boutros M, Huber W (2010) EBImage: an R package for image processing with applications to cellular phenotypes. Bioinformatics 26:979-981

Pautasso M (2007) Scale dependence of the correlation between human population presence and vertebrate and plant species richness. Ecol Lett 10:16-24

Peña JM, Torres-Sánchez J, de Castro AI, Kelly M, LópezGranados F (2013) Weed mapping in early-season maize fields using object-based analysis of unmanned aerial vehicle (UAV) images. PLoS ONE 8:e77151

Penone C, Kerbiriou C, Julien J-F, Julliard R, Machon N, Le Viol I (2013) Urbanisation effect on orthoptera: which scale matters? Insect Conserv Divers 6:319-327

Plascencia M, Philpott SM (2017) Floral abundance, richness, and spatial distribution drive urban garden bee communities. Bull Entomol Res. https://doi.org/10.1017/ s0007485317000153 
Pollard G, Roetman P, Ward J (2017) The case for citizen science in urban agriculture research. Fut Food J Food Agric Soc 5:9-20

QGIS Development Team (2018) QGIS geographic information system: open source geospatial foundation

R Development Core Team (2016) R Development Core Team. R A Lang Environ Stat Comput 55:275-286

Ricketts T, Imhoff M (2003) Biodiversity, urban areas, and agriculture: locating priority ecoregions for conservation. Conserv Ecol 8:1

Roussel J-R, Auty D (2018) Airborne LiDAR data manipulation and visualization for forestry applications [R package lidR version 2.0.2]

Speak AF, Mizgajski A, Borysiak J (2015) Allotment gardens and parks: provision of ecosystem services with an emphasis on biodiversity. Urban For Urban Green 14:772-781

Spilková J, Vágner J (2017) Food gardens as important elements of urban agriculture: spatio-developmental trends and future prospects for urban gardening in Czechia. Nor J Geogr. https://doi.org/10.1080/00291951.2017.1404489

Stone C, Webster M, Osborn J, Iqbal I (2016) Alternatives to LiDAR-derived canopy height models for softwood plantations: a review and example using photogrammetry. Aust For 79:271-282

Tscharntke T, Tylianakis JM, Rand TA, Didham Raphael K, Fahrig L, Batary P, Bengtsson J, Clough Y, Crist TO, Dormann CF, Ewers RM, Frund J, Holz RD, Holzschuh A,
Klein AM, Kleijn D, Kremen C, Landis DA, Laurance W, Lindenmayer D, Scherber C, Sodhi N, Steffan-Dewenter I, Thies C, van der Putten WH, Westphal C (2012) Landscape moderation of biodiversity patterns and processes: eight hypotheses. Biol Rev 87:661-685

Turner MG, Donato DC, Romme WH (2013) Consequences of spatial heterogeneity for ecosystem services in changing forest landscapes: priorities for future research. Landsc Ecol 28:1081-1097

Wang R, Gamon JA, Cavender-Bares J, Townsend PA, Zygielbaum AI (2018) The spatial sensitivity of the spectral diversity-biodiversity relationship: an experimental test in a prairie grassland. Ecol Appl 28:541-556

Wolf PR, Dewitt BA (2000) Elements of photogrammetry: with applications in GIS. McGraw-Hill, New York

Wu J (2004) Effects of changing scale on landscape pattern analysis: scaling relations. Landsc Ecol 19:125-138

Yue J, Lei T, Li C, Zhu J (2012) The application of unmanned aerial vehicle remote sensing in quickly monitoring crop pests. Intell Autom Soft Comput 18:1043-1052

Zhang C, Qiu F (2012) Mapping individual tree species in an urban forest using airborne lidar data and hyperspectral imagery. Photogramm Eng Remote Sens 78:1079-1087

Publisher's Note Springer Nature remains neutral with regard to jurisdictional claims in published maps and institutional affiliations. 